Research Article

\title{
Triaxial Shear Test on Hydrochloric Acid-Contaminated Clay Treated by Lime, Crushed Concrete, and Super Absorbent Polymer
}

\author{
Fang Tong, ${ }^{1}$ Qiang $\mathrm{Ma} \mathbb{D}^{2}{ }^{2}$ and Xing $\mathrm{Hu}^{2}$ \\ ${ }^{1}$ Hubei University of Technology Engineering and Technology College, Department of Biochemical Engineering, \\ Wuhan 430068, China \\ ${ }^{2}$ Hubei University of Technology, School of Civil Engineering and Architecture, Wuhan 430068, China \\ Correspondence should be addressed to Qiang Ma; maqiang927@163.com
}

Received 18 April 2019; Revised 4 August 2019; Accepted 22 August 2019; Published 17 October 2019

Academic Editor: Saliha Ilican

Copyright (C) 2019 Fang Tong et al. This is an open access article distributed under the Creative Commons Attribution License, which permits unrestricted use, distribution, and reproduction in any medium, provided the original work is properly cited.

\begin{abstract}
Acid pollution weakens the bearing capacity of subgrade, and discarded concrete occupies land. The mechanical properties of hydrochloric acid-contaminated clay were investigated by triaxial consolidation undrained tests. Also, the theory of diffusion double electric layer was employed to explain the change principle of cohesion and compression characteristics of hydrochloric acid-contaminated clay. In addtion, the curing effects of lime, crushed concrete, and SAP on the shear strength of hydrochloric acid-contaminated clay were compared. The triaxial test results show that cohesion decreased with the increase of hydrochloric acid concentration. The internal friction angle firstly increased and then decreased, and the change of internal friction angle was less affected by acid concentration. The curing effect of crushed concrete was similar to that of lime, which was better than lime. SAP could only improve the cohesion of the hydrochloric acid-contaminated clay; the internal friction angle decreased significantly; the three kinds of curing materials could significantly improve the cohesion of acid-contaminated clay to be higher than the natural clay, improving the shear strength to a certain extent. Additionally, the theory analysis illustrated that due to the change in the thickness of the diffusion layer between the clay particles, the van der Waals force between the particles changed, and the colloidal formation of the micelles led to changes in cohesion. The study can provide references to the treatment of contaminated soil in engineering practice.
\end{abstract}

\section{Introduction}

Waste produced in modern industrial production process infiltrates into soil without being effectively disposed, resulting in changes in physical, mechanical, and chemical properties of soil [1-7]. Shear failure of soil often cause disaster in geotechnical engineering. Therefore, many scholars have studied the shear properties of different contaminated soils. Al-Sanad et al. [8] found that the angle of internal friction of soil decreases with the increase of oil pollution concentration. Sunil et al. [9] conducted triaxial consolidated undrained tests of red loam contaminated by landfill leachate, and the results show that with the increase of leachate concentration, the cohesion of red loam increased and the internal friction angle decreased. Ratnaweera and Meegoda [10] studied fine-grained contaminated soils, and the results show that the shear strength of finegrained soils decreased with the increase of pollutant concentration, and the stress-strain relationship curve decreased with the increase of pollutant concentration. Eltarabily et al. [11] conducted a direct shear test on silty clay contaminated by phosphate at different concentrations, and the results show that with the increase of phosphate concentration, the cohesion of silty clay decreased and the angle of internal friction increased. Gratchev and Towhata [12] carried out triaxial consolidated undrained tests on two kinds of acidcontaminated clay, and the results show that the clay strength of montmorillonite increased with the increase of acid concentration, and the clay strength of kaolin first increased and then decreased. Zhu et al. [13] studied the shear strength characteristics of acid-alkali-contaminated soils with different concentrations. In terms of direct shear 
and triaxial tests, Ma et al. [14] carried out direct shear test on clay contaminated by hydrochloric acid, and the results show that the shear strength of the contaminated clay is decreased to a certain extent as compared to the natural clay.

The change of physical properties of contaminated soil has different degrees of influence on geotechnical engineering and foundation engineering. Therefore, it is very valuable to carry out the study of soil improvement technology to treat contaminated soil and make its mechanical properties meet the requirements of practical engineering application. The commonly used method to improve the mechanical properties of soil is to add curing agent in soil, through the physical and chemical effects of curing agent to change the mechanical properties of the soil. However, at present, there are relatively few studies on the treatment of contaminated soil with curing agent, and most of the studies are to use different curing agents to treat natural soil. Moreover, lime [15-18], cement [19], gypsum [20], fly ash $[21,22]$, and other traditional materials are usually used in curing materials. Researching on the shear properties of soil cured by traditional curing agents, Makki-Szymkiewicz et al. [23] conducted triaxial test on lime-treated silty soil, and the results show that the cohesion increases and the internal friction angle is almost unchanged with the increase of the curing period. Ismail et al. [24] carried out the triaxial test on calcareous soil treated with different types of cement, and analyzed the influence of different types of cement on the shear strength of cement-cured calcareous soil. At the same time, due to the increasingly severe global energy and environmental problems, more and more attention has been paid to the research on the mechanical properties of soil improved by natural materials and solid wastes. Researching on the mechanical properties of soil cured by natural materials, Prabaker and Sridhar [25] conducted triaxial consolidation undrained tests on sisal fiber to treat silty clay, and the results show that sisal fiber can effectively increase the maximum deviatoric stress of clay. Ma et al. [26] put regenerated flax fiber into clay and investigated the shear performance of flax fiber-reinforced clay by unconsolidated and undrained triaxial test, and the tests results show that the shear strength of the flax fiber-cured clay is significantly improved compared with that of the pure clay, but the internal friction angle is small and the cohesion is obviously increased. Researching on the mechanical properties of soil cured by solid waste, Akbulut et al. [27] conducted unconfined compression, shear box, and resonant frequency tests on clayey soils modificated by scrap tire rubber and synthetic fibers to investigate their strength and dynamic properties. Ma et al. [28] studied the shear strength characteristics and working mechanism of the scrap tire strips treated brick, in terms of large-scale direct shear test. According to research by Vieira and Pereira [29], construction waste mixtures are mainly composed of bricks and concrete, and the mechanical properties of construction waste show low variability. Touahamia et al. [30] carried out direct shear tests on the recycled waste materials, and the results show that the shear strength of the waste materials can be significantly improved by crushed concrete. If the crushed concrete in construction waste is reused as a curing agent, it can not only improve the mechanical properties of the soil, but also realize the recycling of construction waste, resource saving, and environmental protection [31, 32]. With the deepening of the research of curing materials, researchers have tested a variety of polymer materials and obtained many considerable scientific research results. Nadler et al. [33] and Levy and Miller [34] used polyacrylamide to effectively improve the water stability of clayey soils. Botero et al. [35] put regenerated polyester resin (PET) fiber into silt and investigated the stress-strain characteristics of fiber-reinforced soil by unconsolidated and undrained shear test, and the results show that PET fiber can greatly improve the ability of soil to resist deformation. SAP (Super Absorbent Polymer) is a new polymer material with excellent water retention, which can be used as a new curing material. In summary, these studies expand the sources and fields of curing materials. However, there are relatively few research studies on the shear strength of acid-contaminated clay cured by lime, crushed concrete waste, and SAP at present.

Therefore, this paper uses traditional curing agent lime and crushed concrete and SAP to treat acid-contaminated clay, to investigate the curing effect of the above materials on acid-contaminated clay, and to compare the differences between the new materials and traditional materials, so as to explore a new way for the treatment of acid-contaminated clay.

\section{Test Scheme}

2.1. Selection of Soil Samples. The clay used in the experiment was taken from a $2.5 \mathrm{~m}$ deep foundation pit located at the new office building of Hubei University of Technology in Wuhan, and its mechanical parameters are listed in Table 1, and its main material composition measured by X-ray fluorescence spectrum (XRF) analysis is listed in Table 2.

\subsection{Preparation of Contaminated Soil. $\mathrm{HCl}$ solution with a} concentration of $36.5 \%$ and distilled water were used for the preparation of acid-contaminated clay [13], the concentrations of dilute hydrochloric acid solutions in the experiment were $1 \%, 3 \%$, and $5 \%$, respectively. Concentrated hydrochloric acid required for the preparation of different concentrations of $\mathrm{HCl}$ solution is listed in Table 3. In order to investigate the effect of the mass percentage of lime, crushed concrete, and super absorbent polymer on the strength of acid-contaminated clay, the mass of lime required for preparing acid-contaminated clay cured by lime of different contents is listed in Table 4 . The mass of crushed concrete waste required for preparing acid-contaminated clay cured by crushed concrete waste of different contents are listed in Table 5, and the mass of SAP required for preparing acid-contaminated clay cured by SAP of different contents is listed in Table 6.

According to the requirements of the Chinese Highway Geotechnical Test Code [36], the selected clay was dried, mashed, and sifted. The weighed dry clay and curing agent was mixed with the prepared contaminated solution evenly, 
TABle 1: Physical and mechanical properties of undisturbed soil.

\begin{tabular}{lccccc}
\hline Parameter & Density $\left(\mathrm{g} \cdot \mathrm{cm}^{-3}\right)$ & Specific gravity of soil particle $G_{s}$ & Moisture content (\%) & Liquid limit (\%) & Plastic limit (\%) \\
\hline Value & 1.82 & 2.69 & 32 & 48.2 & 20.1 \\
\hline
\end{tabular}

TABle 2: Material composition (unit: \%).

\begin{tabular}{lcccccccccc}
\hline $\mathrm{SiO}_{2}$ & $\mathrm{MgO}$ & $\mathrm{CaO}$ & $\mathrm{Al}_{2} \mathrm{O}_{3}$ & $\mathrm{Fe}_{2} \mathrm{O}_{3}$ & $\mathrm{~K}_{2} \mathrm{O}$ & $\mathrm{Na}_{2} \mathrm{O}$ & $\mathrm{TiO}_{2}$ & $\mathrm{P}_{2} \mathrm{O}_{5}$ & MnO & Ignition loss \\
\hline 63.17 & 1.00 & 0.43 & 15.95 & 6.85 & 2.02 & 0.37 & 0.91 & 0.046 & 0.057 & 9.20 \\
\hline
\end{tabular}

TABLE 3: Concentrated hydrochloric acid required for the preparation of different concentrations of $\mathrm{HCl}$ solution.

\begin{tabular}{lccc}
\hline \multirow{2}{*}{ Required material } & \multicolumn{3}{c}{$\mathrm{HCl}$} \\
& $1 \%$ & $3 \%$ & $5 \%$ \\
\hline $\mathrm{HCl}$ solution with a concentration of $36.5 \%$ & $4 \mathrm{ml}$ & $12 \mathrm{ml}$ & $20 \mathrm{ml}$ \\
\hline
\end{tabular}

TABLE 4: Mass of lime required for preparing acid-contaminated clay cured by lime of different contents.

\begin{tabular}{lccc}
\hline \multirow{2}{*}{ Required material } & \multicolumn{3}{c}{ Acid-contaminated clay cured by } \\
& $1.0 \%$ & $1.5 \%$ & $3.0 \%$ \\
\hline Lime & $1.72 \mathrm{~g}$ & $2.58 \mathrm{~g}$ & $5.16 \mathrm{~g}$ \\
\hline
\end{tabular}

TABLE 5: Mass of crushed concrete waste required for preparing acid-contaminated clay cured by crushed concrete waste of different contents.

\begin{tabular}{lccc}
\hline \multirow{2}{*}{ Required material } & \multicolumn{3}{c}{$\begin{array}{c}\text { Acid-contaminated clay cured by } \\
\text { crushed concrete waste }\end{array}$} \\
& $5.0 \%$ & $10 \%$ & $15 \%$ \\
\hline Crushed concrete waste & $8.59 \mathrm{~g}$ & $17.19 \mathrm{~g}$ & $25.78 \mathrm{~g}$ \\
\hline
\end{tabular}

TABLE 6: Mass of SAP required for preparing acid-contaminated clay cured by SAP of different contents.

\begin{tabular}{lccc}
\hline \multirow{2}{*}{ Required material } & \multicolumn{3}{c}{ Acid-contaminated clay cured by SAP } \\
& $5.0 \%$ & $10 \%$ & $15 \%$ \\
\hline SAP & $8.59 \mathrm{~g}$ & $17.19 \mathrm{~g}$ & $25.78 \mathrm{~g}$ \\
\hline
\end{tabular}

and the moisture content of the sample was controlled at $20 \%$ by adding water. Then, the acid-contaminated clay was cured for 24 hours to make its moisture content stable. The samples were compacted in 5 layers, and the compaction degree of the samples was controlled, eventually the samples of $39.1 \mathrm{~mm}$ (diameter) $\times 80 \mathrm{~mm}$ (height) were made.

2.3. Test Methods and Procedures. The experimental operation processes in this paper are shown in Figure 1. According to the Chinese Geotechnical Test Method Standard (GB/ t50123-1999), the contaminated clay samples prepared according to different influencing factors were tested by a series of triaxial consolidation and undrained tests. The confining pressure was $100 \mathrm{kPa}, 200 \mathrm{kPa}$, and $300 \mathrm{kPa}$ respectively, and the shear rate was $0.5 \%$ strain per minute.

\section{Test Results and Analysis}

3.1. Triaxial Undrained Consolidation Test of Manually Mixed Acid-Contaminated Clay. Polluted clay with different concentrations of hydrochloric acid was prepared for triaxial consolidation and undrained test. The triaxial test data were processed by the $p-q$ method to study the variation of internal friction angle and cohesion of hydrochloric acidcontaminated clay. The $p-q$ method is a simple arrangement method of experimental results [37], in which,

$$
\begin{aligned}
& p=\frac{\sigma_{1}+\sigma_{3}}{2}, \\
& q=\frac{\sigma_{1}-\sigma_{3}}{2},
\end{aligned}
$$

where the $p-q$ plane is the meridian plane, $p$ for the spherical stress and $q$ for the deviatoric stress, $\sigma_{1}$ for the major principal stress, $\sigma_{3}$ for minor principal stress.

Mathematical software Matlab was employed for linear fitting, and the following $p-q$ relationship curve and linear fitting formula were obtained, as shown in Figure 2.

If the intercept and slope of the fitting line are $a$ and $\tan \alpha$, respectively, the following formula can be obtained:

$$
\begin{aligned}
& c=\frac{a}{\cos \varphi}, \\
& \varphi=\sin ^{-1}(\tan \alpha),
\end{aligned}
$$

where $c$ is cohesion and $\varphi$ is the internal friction angle.

Cohesion $(c)$ and internal friction angle $(\varphi)$ of acidcontaminated soils can be calculated by formula (3), and the calculated $c$ and $\varphi$ are shown in Figure 3 .

As can be seen from Figure 3, with the increase of the concentration of hydrochloric acid, the cohesion first decreased and then increased, while the internal friction angle first increased and then decreased. When the acid concentration was $1 \%$, the changes in the internal friction angle and cohesion were small, the cohesion decreased by about $15 \%$ while the internal friction angle basically did not increase, which indicates that the soil has a certain tolerance to acid at a low concentration and the structure of soil does not change significantly. When acid concentration was about $3 \%$, the cohesion substantially declines, falling to $24.9 \mathrm{kPa}$, and the internal friction angle was relatively higher than that with acid concentration of $1 \%$, the cause is when the clay was polluted by hydrochloric acid, the erosion of soil leads to the destruction of the oxide which provided cementation and coherence function in clay, and 


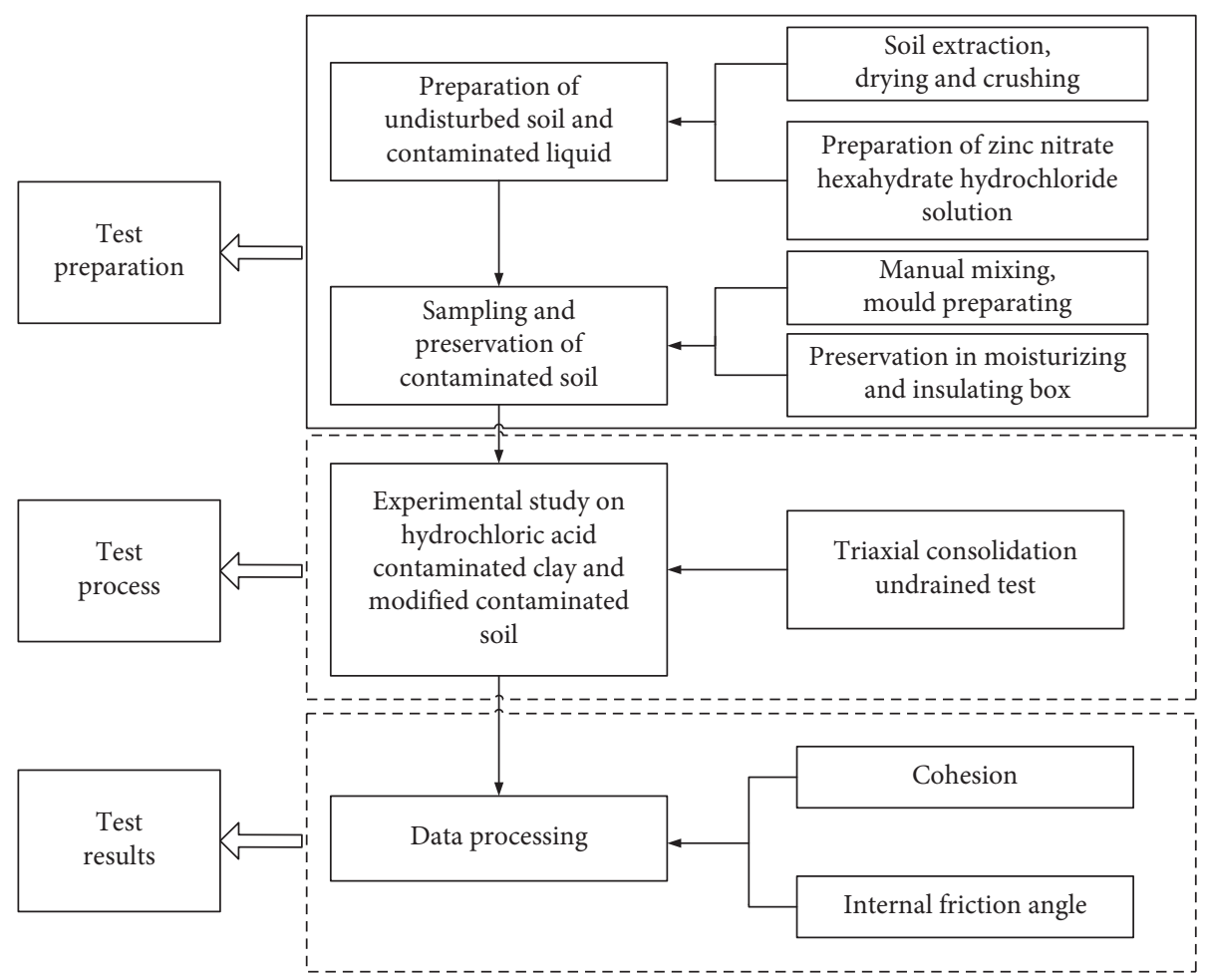

FIgURE 1: Schematic diagram of the test scheme.

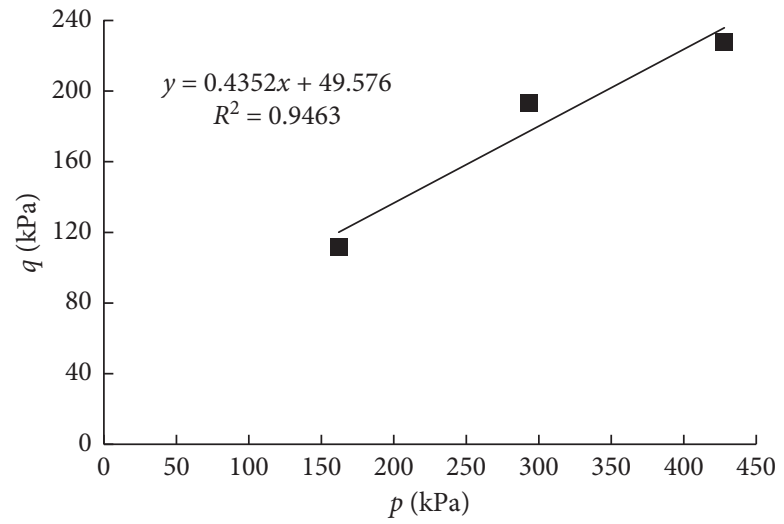

(a)

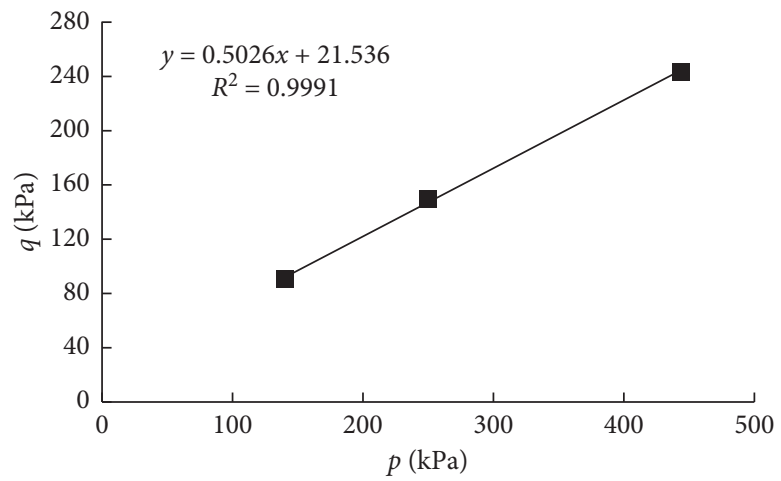

(c)

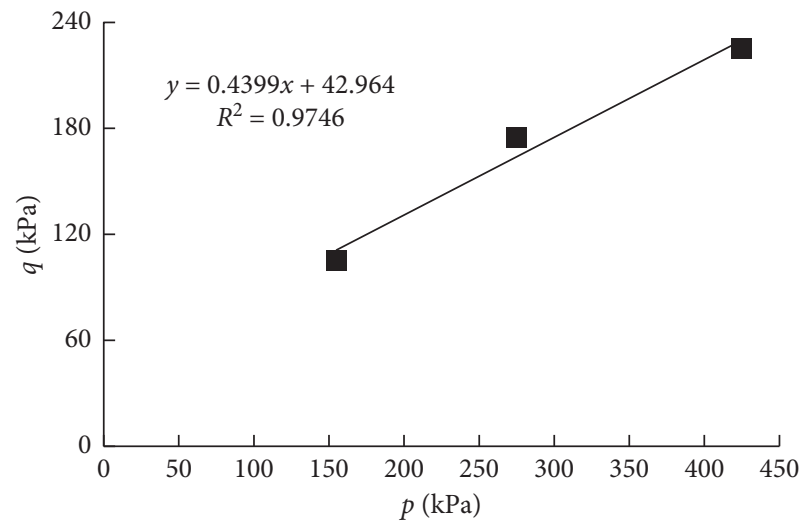

(b)

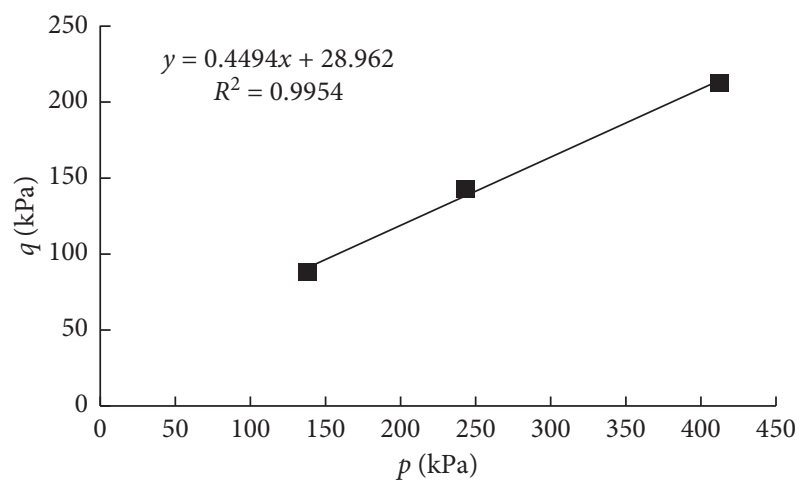

(d)

FIGURE 2: p- $q$ relation curves of acid-contaminated clay with different concentrations. (a) Uncontaminated soil. (b) $1 \%$ HCL. (c) $3 \%$ HCL. (d) $5 \%$ HCL. 


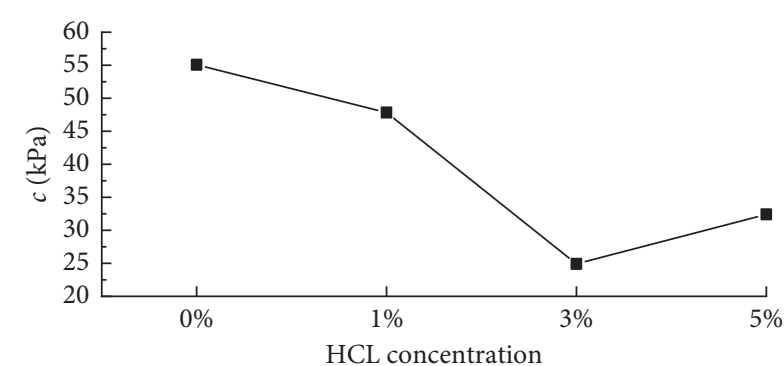

(a)

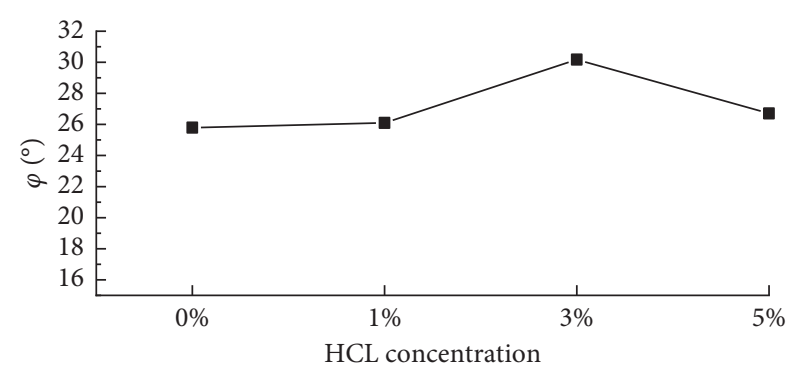

(b)

Figure 3: $c$ and $\varphi$ of acid-contaminated clay with different acid concentrations. (a) Cohesion variation. (b) Internal friction angle variation.

the crumb structure of soil grain was broken, the bonding between soil particles was reduced, which caused soil porosity increase, structure looses, and shear strength decreases. When the acid concentration was $5 \%$, the cohesion of the soil decreased greatly compared with that of the uncontaminated soil, and the internal friction angle also decreased slightly. At this time, the formation and precipitation of new salt also increased the cohesive force between soil particles to some extent. In general, the cohesion tended to decrease with the increase of acid concentration, while the change of internal friction angle was small.

3.2. Theoretical Analysis of Experimental Results. In order to clear the change laws of mechanical properties of hydrochloric acid-contaminated clay and grasp the chemical principle of the change, the mechanism of micro interface between clay particles was analyzed by introducing the theory of diffusion double electric layer and considering of van der Waals force.

\subsubsection{Diffuse Double-Layer Theory of Clay Particles.} Previous studies showed that the surface of clay particles was negatively charged [38]. The electrons were attracted to each other in the opposite direction and repelled each other in the same direction. On the surface of clay particles, positive cations were bound to be adsorbed. Thereafter, a layer of negative charge was formed on the surface of clay particles, and an electric layer corresponding to the positive charge of the negative ions was formed to maintain the balance of charge. Charged clay particles created a tiny electric field in which polar water molecules were oriented, with the positive pole pointing toward the surface of particles. When cations gathered together on the surface of clay particles, molecular thermal motion and differential concentration of cations would be generated, which then caused irregular diffusion movement of cations away from the clay interface. The surface of clay particles would form a layer of close and regular cations. In addition to this layer of cations, a layer of disordered cations with positive charges would be distributed, forming a diffusion double layer. The double-layer structure of a single clay particle is shown in Figure 4, and the arrangement structure of water adsorption between two clay platelets with negative charge is shown in Figure 5.

3.2.2. Theoretical Analysis of Electric Double Layer of Clay. Ionic potential energy $E_{i}$ with valence $i$ in the electric field can be expressed as

$$
E_{i}=v_{i} e \psi
$$

where $v_{i}$ is ion valence, $e$ is unit charge $\left(e=4.8 \times 10^{-19} \mathrm{C}\right)$, and $\psi$ is the potential energy (unit: V). According to the Boltzmann distribution, the ion concentration $n_{i}$ with valence $i$ can be expressed as

$$
n_{i}=n_{i 0} \exp \left(\frac{E_{i 0}-E_{i}}{k T}\right),
$$

where $n_{i 0}$ is the ion concentration on the surface far away from the charge, $E_{i}$ and $E_{i 0}$ are the potential energy of the ions with valence $i$ and the potential energy of the surface far away from the charge, $k$ is Boltzmann constant, and $T$ is the absolute temperature (unit: $\mathrm{K}$ ).

Combining formulas (3) and (4), ion concentration and electrical potential can be connected. When $E_{i 0}=0$,

$$
n_{i}=n_{i 0} \exp \left(\frac{-v_{i} e \psi}{k T}\right) .
$$

The charge density of the electric double layer can be expressed as

$$
\rho=e \sum v_{i} n_{i},
$$

where $\rho$ is the charge density.

Substituting formula (6) into formula (5),

$$
\rho=e \sum v_{i} n_{i 0} \exp \left(\frac{-v_{i} e \psi}{k T}\right) .
$$

Substituting formula (7) into the Poisson formula of the electrical potential at each point,

$$
\frac{\mathrm{d}^{2} \psi}{\mathrm{d} x^{2}}=-\frac{4 \pi \rho}{D}=-\frac{4 \pi e}{D} \sum n_{i 0} v_{i} \exp \left(\frac{-v_{i} e \psi}{k T}\right),
$$

where $x$ is the distance between each point and the surface of the charge and $D$ is the dielectric constant.

When there are single species of anions and cations in the solution, at this point $i=2$, and formula (8) can be simplified to the Poisson-Boltzmann formula: 


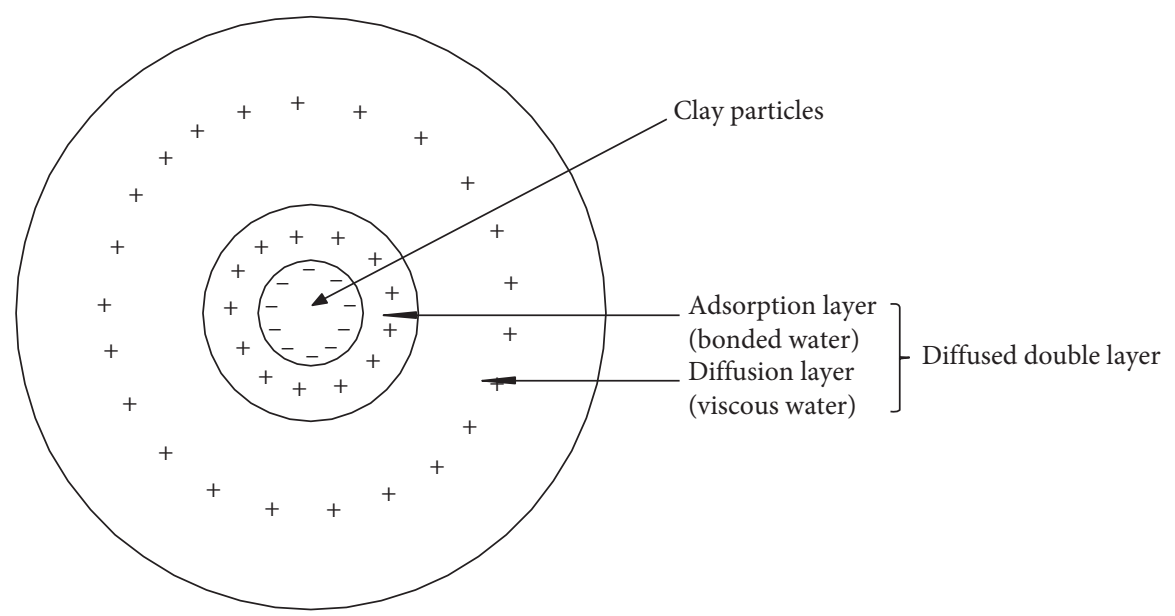

Figure 4: Double-layer structure diagram of clay particle.

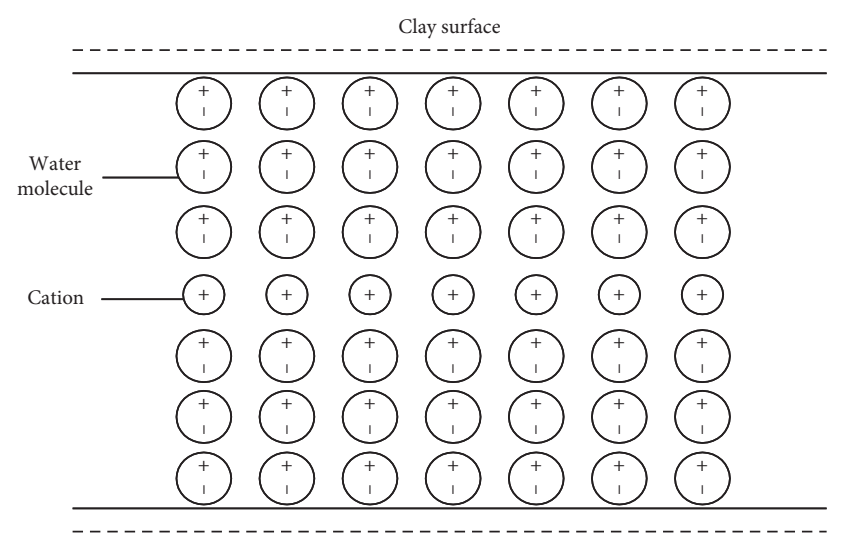

Clay surface

Figure 5: Arrangement structure of adsorbed water between clay sheets.

$$
\frac{\mathrm{d}^{2} \psi}{\mathrm{d} x^{2}}=\frac{8 \pi e v n_{0}}{D} \sinh \frac{v e \psi}{k T} .
$$

Through transformation, formula (10) can be written as

$$
\begin{aligned}
\frac{\mathrm{d}^{2} y}{\mathrm{~d} \tau^{2}} & =\sinh y, \\
y & =\frac{v e \psi}{k T}, \\
\tau & =K x, \\
K & =e v \sqrt{\frac{8 \pi n_{0}}{D k T}},
\end{aligned}
$$

where $\tau$ and $y$ are dimensionless, and the formula for the thickness of electric double layer can be obtained [38]:

$$
s=\frac{1}{K}=\frac{1}{e v} \sqrt{\frac{D k T}{8 \pi n_{0}}} .
$$

Formula (14) shows that the thickness of the double layer $(s)$ is inversely proportional to cationic valency $(v)$ and electrolyte concentration $\left(n_{0}\right)$, and proportional to the square root of temperature $(T)$ and dielectric constant $(D)$.

Also, the energy generated by the attraction and repulsive forces between the two particles can be calculated by the Lanna-Jones formula [38]:

$$
E=-\frac{\Lambda}{d^{6}}
$$

where $\Lambda$ is a constant and $d$ is the distance between molecules. Formula (15) illustrates that the suction between clay particles depends mainly on the distance between the particles. When the thickness of the electric double layer increases, the distance between the clay particles increases, the suction decreases, and the shear strength of the soil will reduce, and vice versa.

The thickness of the diffusion double layer directly affects the cohesion of clay if the diffusion layer is relatively thin, and the distance between clay particles is relatively close, the shear strength of clay increases, and the compressibility decreases. On the contrary, if the diffusion layer is thicker, the clay particles are more dispersed, the shear strength of the clay decreases, and the compressibility increases.

When clay is contaminated by hydrochloric acid, the minerals in clay react with the acid in a series of chemical reactions. Oxide decomposition reaction in hydrochloric acid-contaminated soil produces compounds and water, and the generated water flow into the soil increases the porosity of the clay particles; the main compounds in clay are silicon oxide, ferric oxide, and alumina which are hydrophilic, and the increased water enlarges the porosity, increases the thickness of the diffusion layer, reduces the cohesion of clay particles, and reduces the shear strength of clay as well.

With the addition of hydrochloric acid, ferric oxide and alumina in the clay react with hydrochloric acid and produce free water and redundant cation between clay particles, and free iron oxide reacts with water to generate a small amount of hydrated ferric oxide and further produces iron hydroxide colloid, and the reaction process is as follows: 


$$
\begin{aligned}
6 \mathrm{HCl}+\mathrm{Fe}_{2} \mathrm{O}_{3} & =2 \mathrm{FeCl}_{3}+3 \mathrm{H}_{2} \mathrm{O} \\
6 \mathrm{HCl}+\mathrm{Al}_{2} \mathrm{O}_{3} & =2 \mathrm{Al}_{2} \mathrm{Cl}_{3}+3 \mathrm{H}_{2} \mathrm{O} \\
\mathrm{Fe}_{2} \mathrm{O}_{3}+\mathrm{H}_{2} \mathrm{O} & =2 \mathrm{FeOOH} \\
\mathrm{FeOOH}+\mathrm{e}^{-}+3 \mathrm{H}^{+} & =\mathrm{Fe}^{2+}+2 \mathrm{H}_{2} \mathrm{O} \\
\mathrm{Fe}^{2+}+\mathrm{OH}^{-} & \rightleftharpoons \mathrm{Fe}(\mathrm{OH})_{2} \text { (colloform) } \\
\mathrm{Fe}^{3+}+\mathrm{OH}^{-} & \rightleftharpoons \mathrm{Fe}(\mathrm{OH})_{3} \text { (colloform) }
\end{aligned}
$$

In this process, electrolyte and free water were produced in a large amount; the amount of electrolyte increased and resulted in rising of electrolyte concentration $\left(n_{0}\right)$. Meanwhile, the solid compound generated solution, thus increased the dielectric constant of water $(D)$, and the exothermic reaction increased the temperature formula (14) shows that the diffusion layer thickness $(s)$ increases and the distance between the particles increases; thus, from formula (15), it can be concluded that the van der Waals force of clay particles decreases. In addition, in the reaction process, $\mathrm{SiO}_{2}$ in clay particles will also produce certain weak acids to form a sol structure:

$$
\begin{aligned}
\mathrm{SiO}_{2}+\mathrm{H}_{2} \mathrm{O} & =\mathrm{H}_{2} \mathrm{SiO}_{3} \\
\mathrm{H}_{2} \mathrm{SiO}_{3} & \rightleftharpoons 2 \mathrm{H}^{+}+\mathrm{SiO}_{2-3}
\end{aligned}
$$

When the acid concentration is below a certain value, clay will produce large amounts of colloidal structures such as positive sol $\mathrm{Fe}(\mathrm{OH})_{3}$ and ionized $\mathrm{SiO}_{2-3}$ adsorbed on $\mathrm{SiO}_{2}$ to form a negatively charged colloid, and the emergence of the micelle structure significantly increases the porosity of the clay; therefore, the distance between clay particles is further increased. It can be concluded from formula (15) that the suction continues to decrease and the soil has the lowest shear strength. The structural formula of $\mathrm{Fe}(\mathrm{OH})_{3}$ micelle is shown in Figure 6, and the structural diagram is shown in Figure 7.

Chemical formula (24) is the micelle structural formula of $\mathrm{SiO}_{2}$ sol, and the structural diagram is shown in Figure 8.

$$
\left[\left(\mathrm{SiO}_{2}\right)_{\mathrm{m}} n \mathrm{SiO}^{2-3} \cdot 2(n-x) \mathrm{H}^{+}\right]^{2 x-} \cdot 2 x \mathrm{H}^{+}
$$

When the acid concentration is $1 \%$, certain free water is generated when it is added to the clay, the clay particle diffusion layer becomes thicker, the distance between clay particles increases, the attraction decreases, and the cohesion decreases. With the increase of acid concentration, a certain amount of micelle structure will be generated between clay particles, the distance between clay particles will further increase, the suction between particles will further reduce, and the cohesion will continue to decline. But when the acid concentration exceeds a certain value, $\mathrm{H}^{+}$increases gradually and $\mathrm{OH}^{-}$decreases gradually; then, the reverse reaction of the reaction formulas (21) and (23) takes place, and the micelle structure will reduce, thus reducing the distance between the clay particles to a certain extent, while van der
Waals force between particles increases, the cohesion rises slightly, but it is still far below the soil from pollution. Consistent with the results of the consolidated undrained triaxial test (Figure 3), the cohesion first decreased with the increase of acid concentration and then increased when the acid concentration was $5 \%$.

\subsection{Triaxial Test of Lime-Cured Acid-Contaminated Clay.} Lime, as a traditional alkaline curing agent, can neutralize the acidic substances, increase the $\mathrm{pH}$, and improve the mechanical properties of acid-contaminated clay to a certain extent. Through the consolidation undrained triaxial test of lime-cured acid-contaminated clay, the engineering properties were investigated. The $p-q$ relationship curves of clay which was contaminated by hydrochloric acid at a concentration of $3 \%$ and cured by lime with different mass percentages were obtained in the test, as shown in Figure 9.

The data in Figure 9 can be calculated by formula (2) to obtain the variations of internal friction angle and cohesion of acid-contaminated clay after lime curing, as shown in Figure 10.

It can be seen clearly from Figure 10, the cohesion of natural clay reduced significantly after contaminated by hydrochloric acid at a concentration of 3\%; it fell about by $55 \%$. With the use of lime at the mass percentage of $3 \%$ for stabilization, the cohesion went to $52.34 \mathrm{kPa}$ from $24.91 \mathrm{kPa}$, which was close to that of the natural clay after treatment, and with the increase of mass percentage of mixed lime, cohesion increased and got to be greater than that of the natural clay, and it rose to $72.95 \mathrm{kPa}$ in peak; the promotion was obvious.

It can be seen from Figure 11 that internal friction changed in a small range, after contaminated by $3 \%$ of hydrochloric acid, the internal friction angle of the clay increased from $25.7^{\circ}$ to $30^{\circ}$; thereafter, the clay was mixed with lime and then the internal friction angle further raised and reached the peak at lime mass percentage of $1 \%$, to $33.5^{\circ}$. When the mass percentage of lime was $1.5 \%$, the internal friction angle decreased sharply, lower than that of 3\% acidcontaminated clay and slightly higher than that of natural clay.

With the increase of the content of curing agent, the cohesion increased obviously, while the internal friction angle first increased and then decreased. When the mass percentage of lime was $1.5 \%$, the angle of internal friction showed a trend of decrease, which had a beneficial effect on the shear strength of soil. The mass percentage of relatively favorable lime was about $1 \%$, which increased both the cohesion and the internal friction angle.

\subsection{Triaxial Test of Crushed Concrete-Cured Acid-Contami-} nated Clay. Triaxial tests on clay contaminated by hydrochloric acid at a concentration of 3\% after the addition of crushed concrete waste were carried out, and the $p$ - $q$ relation curves of acid-contaminated clay treated by crushed concrete are shown in Figure 12.

According to the data in Figure 12, formula (2) can be used to calculate internal friction angle and cohesion, and 


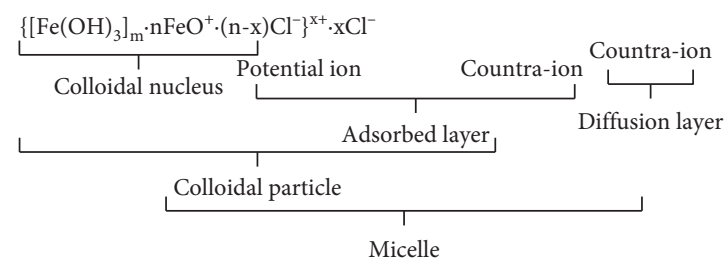

FIGURE 6: Structure formula of micelle.

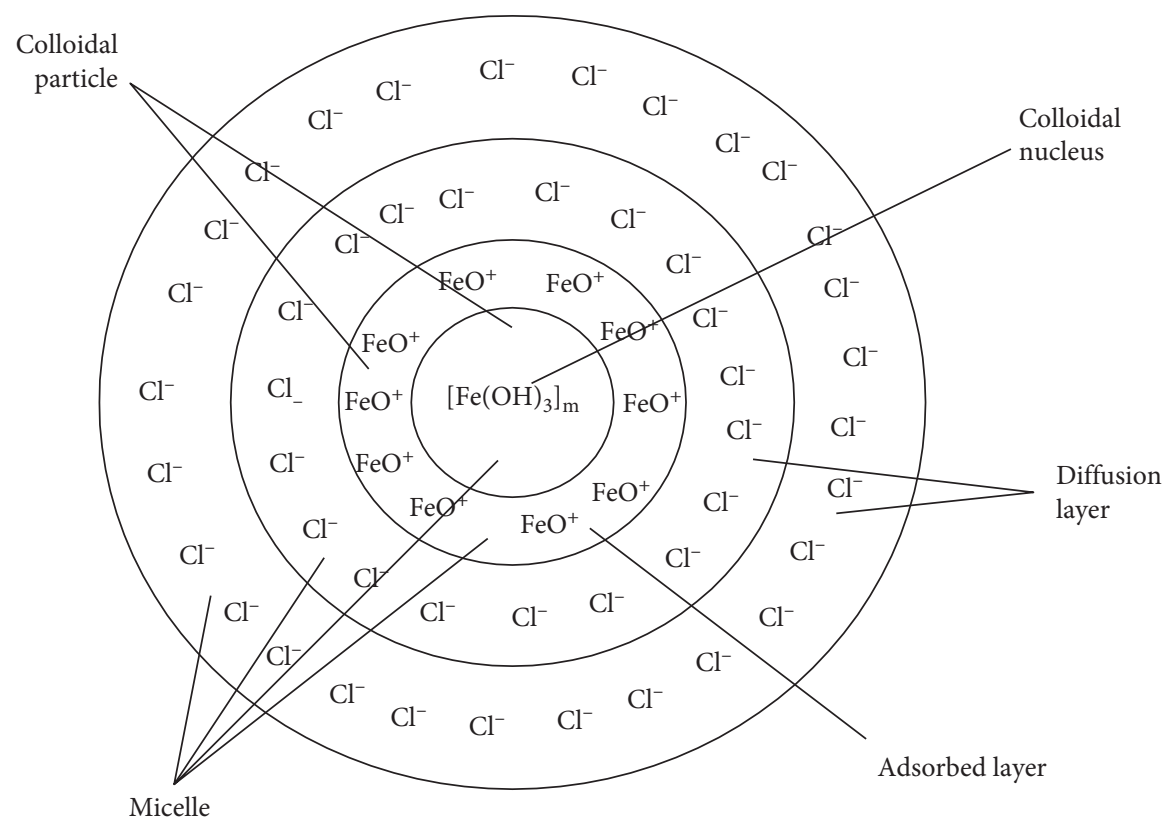

FIgURE 7: Diagram of $\mathrm{Fe}(\mathrm{OH})_{3}$ micelle structure.

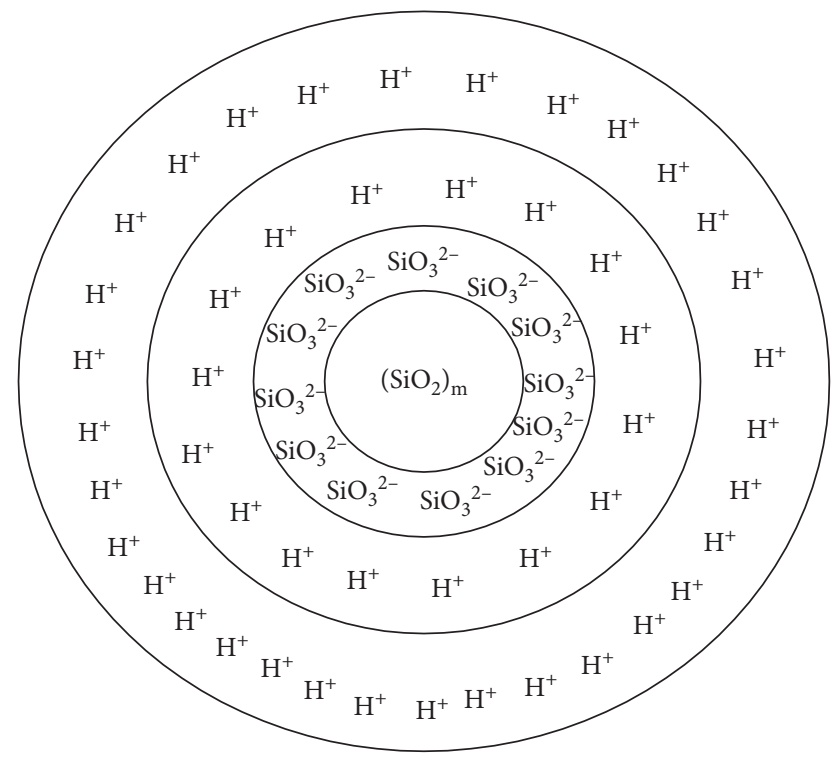

Figure 8: Schematic diagram of $\mathrm{SiO}_{2}$ micelles.

the variation rules of internal friction angle and cohesion of acid-contaminated clay at a concentration of 3\% after curing of crushed concrete waste are as shown in Figures 13 and 14 .
Figure 13 shows that the cohesion increases slowly after the treatment with crushed concrete waste at 5\% mass percentage, which is lower than that of natural clay soil, and increases with the mass percentage of crushed concrete. When the crushed concrete with a mass percentage of $10 \%$ is added, the cohesion of clay is greatly improved, rising to $58.07 \mathrm{kPa}$. When the mass percentage is $15 \%$, the cohesion rises to $77.23 \mathrm{kPa}$. It can be concluded that the addition of crushed concrete waste can improve the cohesion of the clay, and the improving rate is the fastest at the mass percentage is in the range of $5 \%$ to $10 \%$.

Figure 14 illustrates that after adding 5\% mass percentage of crushed concrete, the friction angle of acidcontaminated clay decreases to the same level as natural clay. With the increase of mass percentage of crushed concrete waste, the internal friction angle rises to be slightly higher than that of acid-contaminated clay. In low mass percentage, the alkaline substances in crushed concrete waste reacts with the acid to produce water, which decreases the friction among the clay particles, and the internal friction angle decreased, but when the mass of added crushed concrete exceeds a certain percentage, the added crushed concrete embedded into the clay particles and interlocked, thus increasing the friction between the clay particles and improving the internal friction angle of clay. 


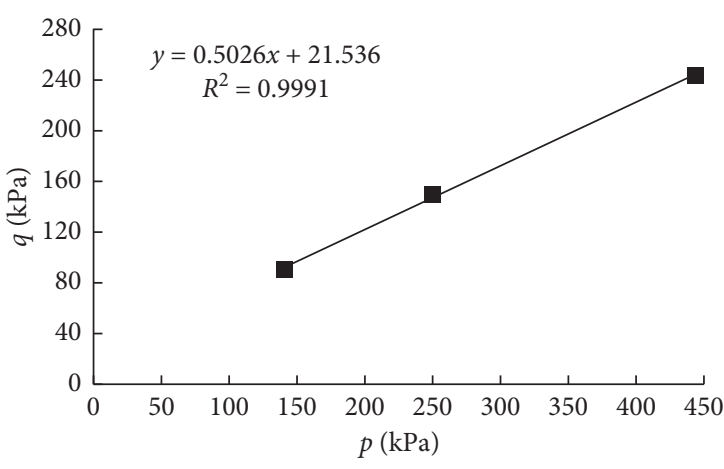

(a)

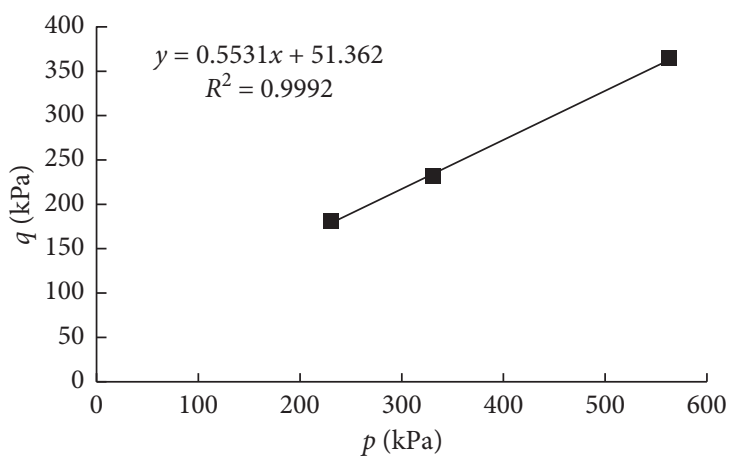

(c)

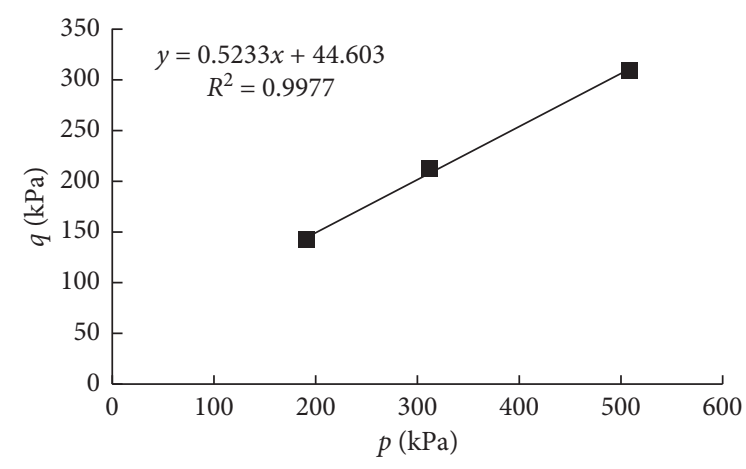

(b)

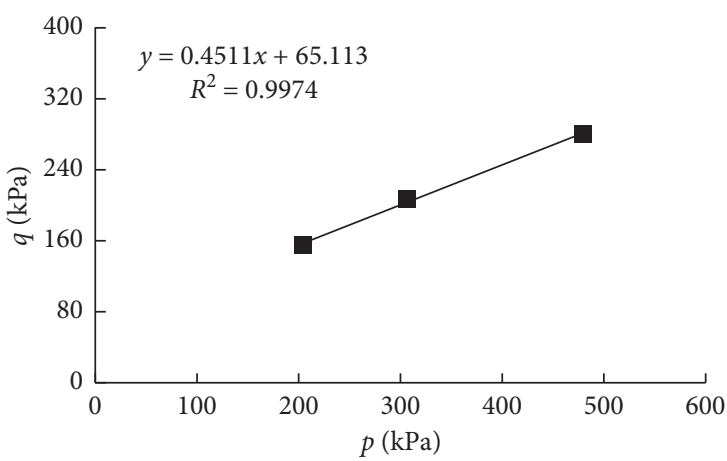

(d)

FIGURE 9: $p$ - $q$ relationship of acid-contaminated clay cured by lime. (a) $3 \%$ HCL concentration. (b) $0.5 \%$ lime content. (c) $1.0 \%$ lime content. (d) $1.5 \%$ lime content.

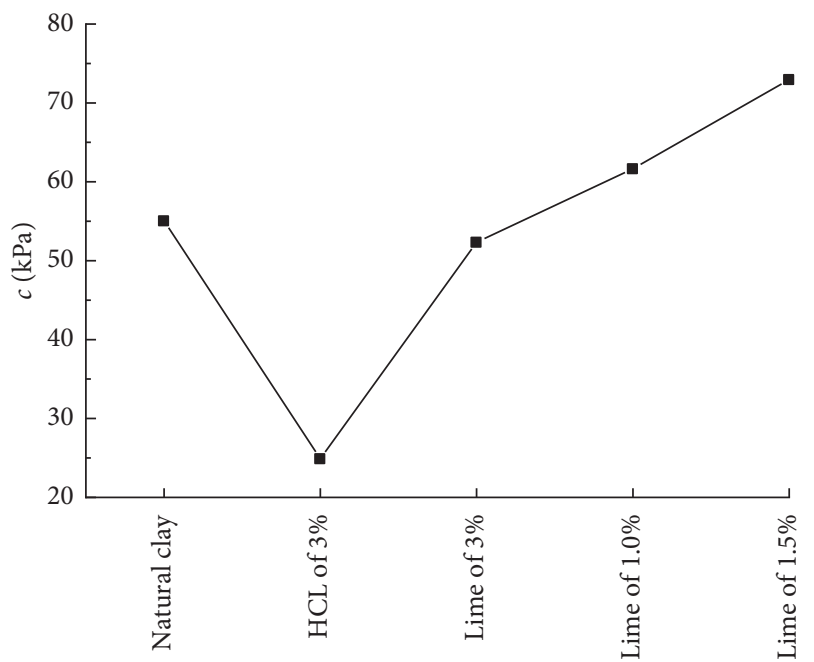

Figure 10: Variation in cohesion of lime-cured acid-contaminated clay.

It can be concluded that the internal friction angle and cohesion of acid-contaminated clay increase with the increase of the mass percentage of crushed concrete waste, indicating that the crushed concrete waste can improve the shear strength of acid-contaminated clay.

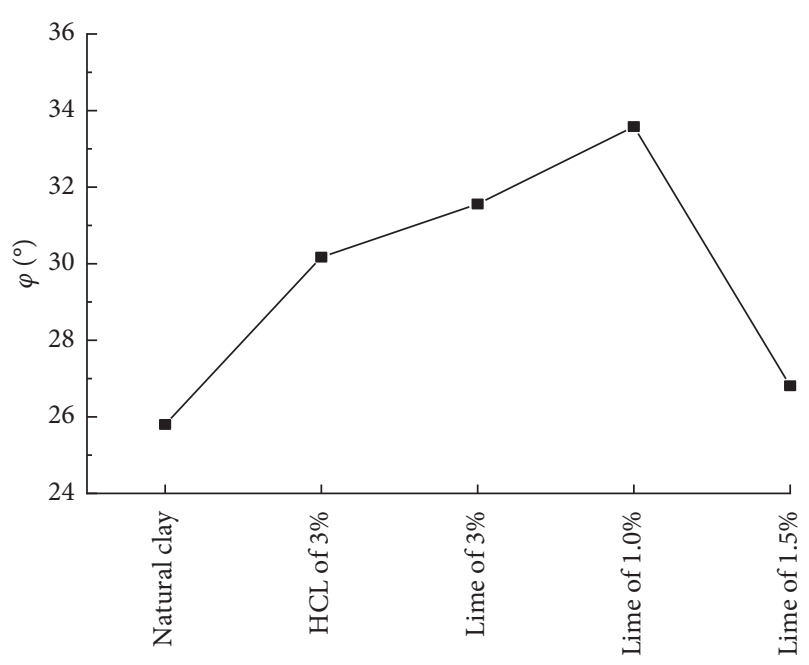

FIGURE 11: Variation in internal friction angle of lime-cured acidcontaminated clay.

3.5. Triaxial Test of SAP-Treated Acid-Contaminated Clay. Triaxial tests on clay contaminated by hydrochloric acid at a concentration of $3 \%$ after the addition of SAP were carried out, to study the change of cohesion and internal friction angle by the undrained triaxial consolidation test, and the test data are shown in Figure 15. 


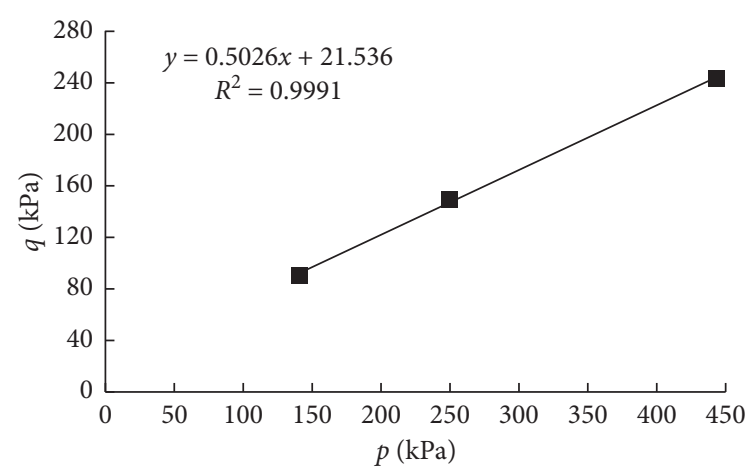

(a)

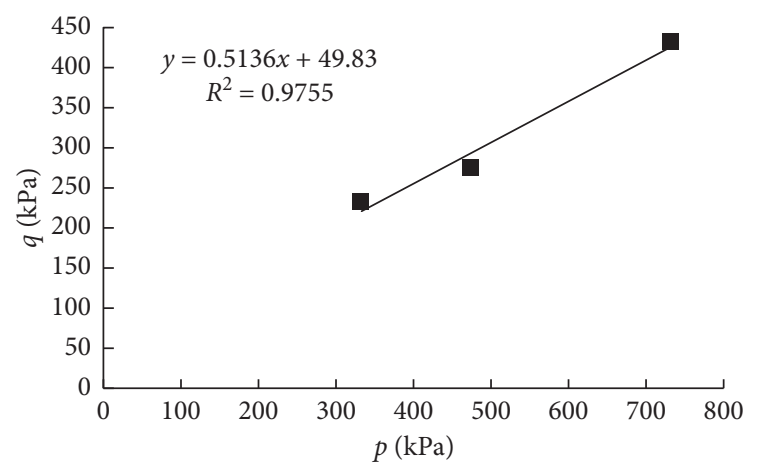

(c)

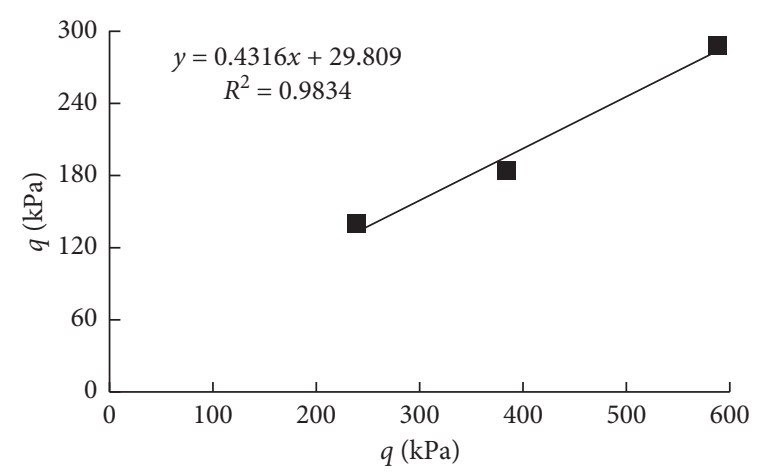

(b)

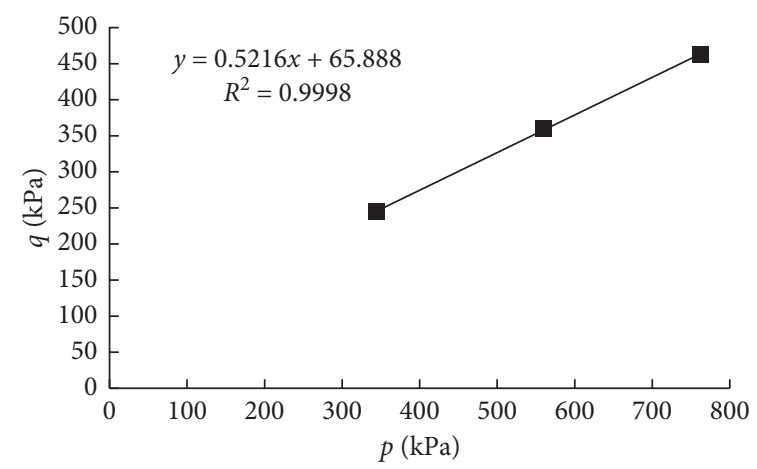

(d)

FIGURE 12: $p-q$ relation relationship of acid-contaminated clay cured by crushed concrete waste. (a) $3 \%$ HCL. (b) $5 \%$ of concrete waste. (c) $10 \%$ of concrete waste. (d) $15 \%$ of concrete waste.

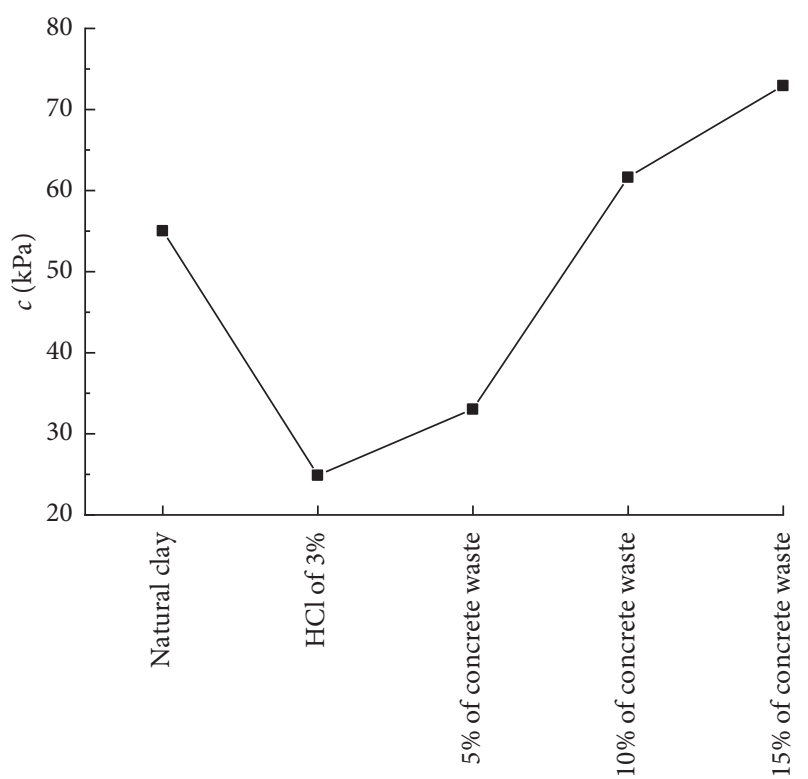

FIGURE 13: Variation in cohesion of crushed concrete waste-cured acid-contaminated clay.

After the calculation and analysis of the data in Figure 15, the variation characteristics of internal friction angle and cohesion of different samples can be obtained, as shown in Figures 16 and 17.

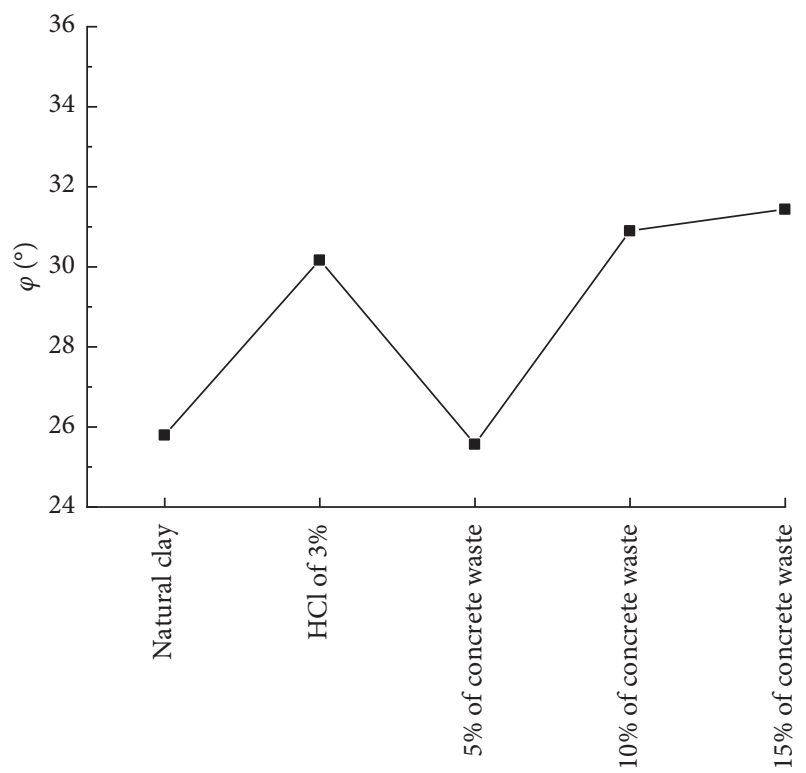

FIGURE 14: Variation in internal friction angle of crushed concrete waste-cured acid-contaminated clay.

From Figure 16 we can see, after the treatment of SAP with a mass percentage of $5 \%$, the cohesion of the acid-contaminated clay is increased, but it is generally higher than that of acid-contaminated clay and lower than the undisturbed clay. 


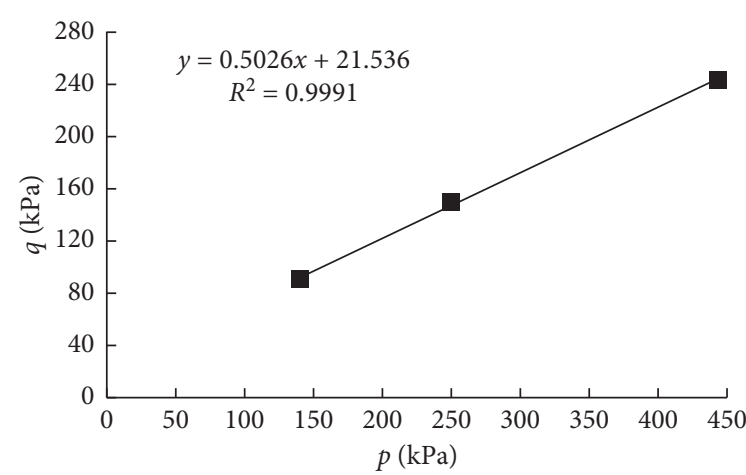

(a)

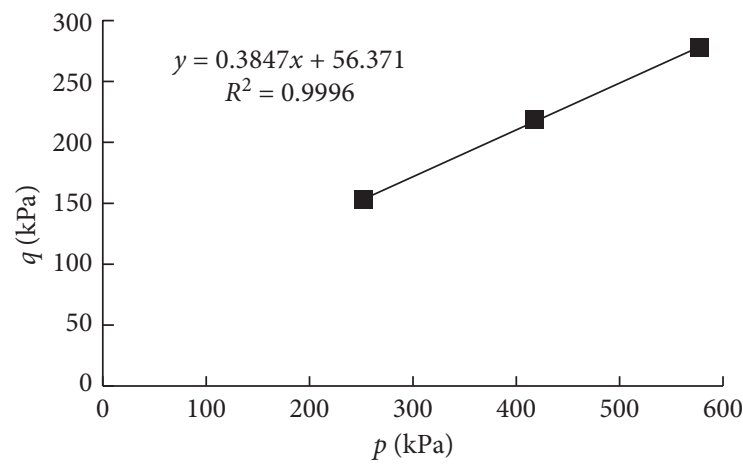

(c)

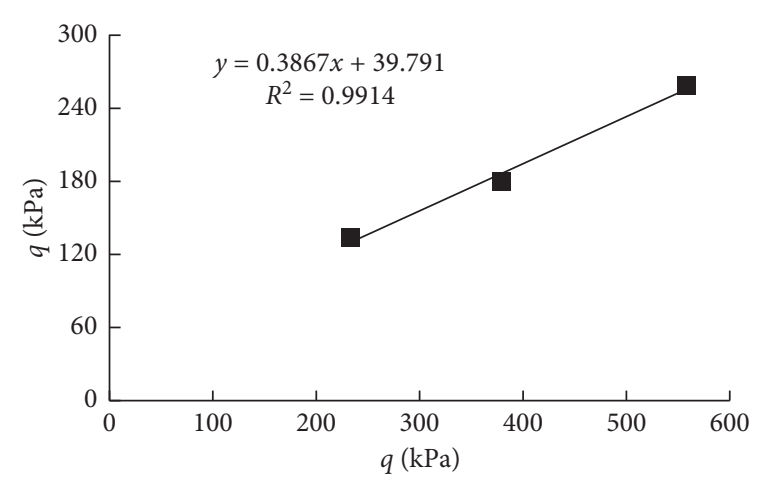

(b)

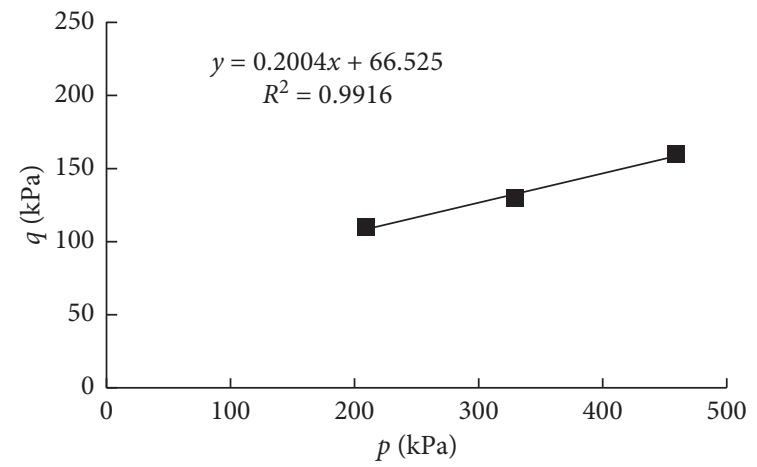

(d)

FIGURE 15: $p$ - $q$ curve of acid-contaminated clay cured by SAP with different mass percentage. (a) $3 \%$ HCL. (b) $5 \%$ SAP. (c) $10 \%$ SAP. (d) $15 \%$ SAP.

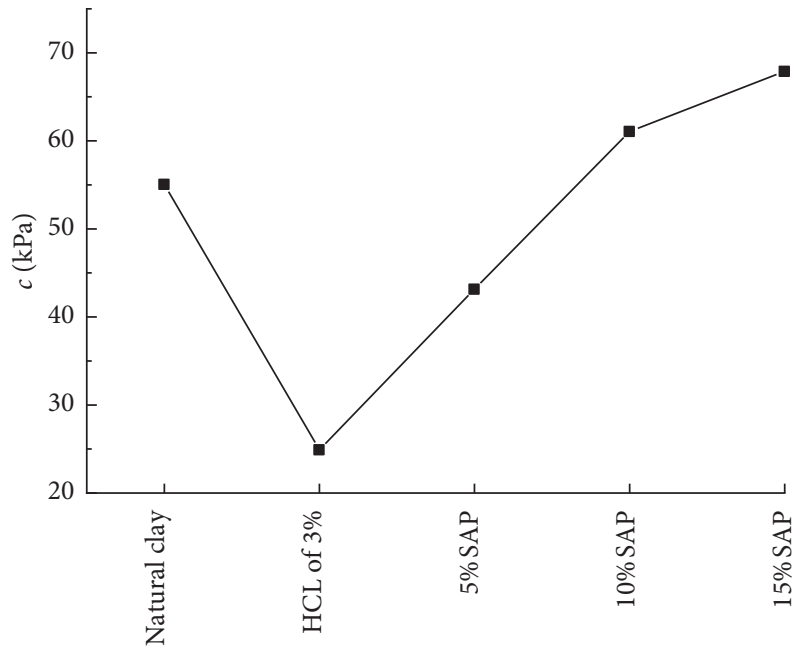

FIGURE 16: Variation in cohesion of SAP-cured acid-contaminated clay.

With the increase of mass percentage of SAP, the cohesion of clay gets further increase, when the mass percentage of SAP is at $10 \%$ and $15 \%$, the cohesion of SAP-cured acid-contaminated clay is higher than the natural clay.

It can be concluded from Figure 17 that, with the increase of mass percentage of SAP, the internal friction angle of the cured acid-contaminated clay presents a significant decline trend, and the decline is large. After addition of SAP

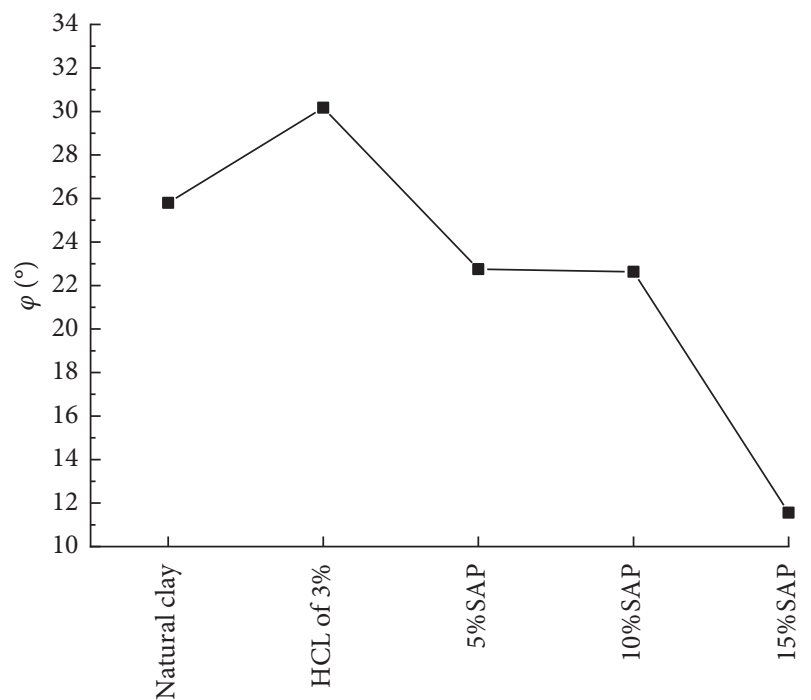

FIGURE 17: Variation in internal friction angle of SAP-cured acidcontaminated clay.

at mass percentage $15 \%$, the internal friction angle falls to $11.56^{\circ}$; it decreased by $55 \%$ compared with undisturbed soil.

\section{Conclusion}

The effect of different hydrochloric acid concentrations on the shear strength of acid-contaminated clay was studied by triaxial shear tests, the solidification effect of the traditional 
curing agent lime and crushed concrete and SAP on the treatment of acid-contaminated clay was investigated, and the differences between the new materials and traditional materials were compared; the following conclusions can be drawn:

(1) The triaxial test results show that with the increase of hydrochloric acid concentration, the cohesion of clay decreases first and then increases, and the internal friction angle increases first and then decreases. In general, the shear strength of acid-contaminated clay decreases with the increase of acid concentration. When the acid concentration is below a certain value, clay will produce large amounts of colloidal structure such as positive sol $\mathrm{Fe}(\mathrm{OH})_{3}$ and ionized $\mathrm{SiO}_{2-3}$ adsorbed on $\mathrm{SiO}_{2}$ to form negatively charged colloidal, and the emergence of the micelle structure significantly increases. But when the acid concentration exceeds a certain value, $\mathrm{H}^{+}$increases gradually and $\mathrm{OH}^{-}$decreases gradually; therefore, the micelle structure will reduce.

(2) The acid-contaminated clay was cured by lime, crushed concrete waste, and SAP. All the three curing materials can significantly improve the cohesion of acid-contaminated clay to be higher than that of natural clay and can improve the shear strength to a certain extent.

(3) When the mass percentage of lime was less than $1 \%$, the internal friction angle increased with the increase of mass percentage, and when the mass percentage was $1.5 \%$, the internal friction angle decreased. In general, the addition of crushed concrete residue has little effect on the internal friction angle. After the addition of SAP, the internal friction angle decreased significantly, and the decline rate accelerated with the increase of SAP mass percentage.

(4) The curing effect of crushed concrete waste is similar to that of lime, a traditional curing agent, and it is superior to lime to some extent. SAP could only improve the cohesion of acid-contaminated clay, and the internal friction angle decreased significantly. The crushed concrete waste and lime thin the diffusion layer by ion exchange and micelles, and the formed cations are adsorbed on the outer surface of the clay particles, thereby improving the shear strength. In addition, the cement in the crushed concrete waste is hydrated to form a gel material, which further improves the shear strength. SPA has a strong hydrophilic group, and the hydrolyzed group reacts with various cations, so that the diffusion layer formed by the cation adsorbed on the outer surface of the soil particle is thinned, and the SPA molecule also has a strong adsorption effect, and the unhydrolyzed SPA adsorbs water molecules, resulting in a significant decrease in the internal friction angle.

\section{Data Availability}

The data used to support the findings of this study are available from the corresponding author upon request.

\section{Conflicts of Interest}

The authors declare that they have no conflicts of interest.

\section{Acknowledgments}

The work in this paper is supported by grants from the National Key R\&D Program of China[grant number 2016YFC0502208], National Natural Science Foundation of China (NSFC) [grant number 51678223], and Green Industrial Project of Hubei University of Technology [grant numbers YXQN2017001 and BSQD12153]. The authors would like to express their appreciation to this financial assistance.

\section{References}

[1] H. A. Al-Sanad and N. F. Ismael, "Aging effects on oil-contaminated Kuwaiti sand," Journal of Geotechnical and Geoenvironmental Engineering, vol. 123, no. 3, pp. 290-293, 1997.

[2] M. Khamehchiyan, A. H. Charkhabi, and M. Tajik, "Effects of crude oil contamination on geotechnical properties of clayey and sandy soils," Engineering Geology, vol. 89, no. 3-4, pp. 220-229, 2007.

[3] S. Nayak, B. M. Sunil, and S. Shrihari, "Hydraulic and compaction characteristics of leachate-contaminated lateritic soil," Engineering Geology, vol. 94, no. 3-4, pp. 137-144, 2007.

[4] A. R. Goodarzi, S. Najafi Fateh, and H. Shekary, "Impact of organic pollutants on the macro and microstructure responses of Na-bentonite," Applied Clay Science, vol. 121-122, pp. 1728, 2016.

[5] D. Turer, "Effect of heavy metal and alkali contamination on the swelling properties of kaolinite," Environmental Geology, vol. 52, no. 3, pp. 421-425, 2007.

[6] S. L. Barbour and N. Yang, "A review of the influence of claybrine interactions on the geotechnical properties of Camontmorillonitic clayey soils from western Canada," Canadian Geotechnical Journal, vol. 30, no. 6, pp. 920-934, 1993.

[7] A. Assa'ad, "Differential upheaval of phosphoric acid storage tanks in aqaba, Jordan," Journal of Performance of Constructed Facilities, vol. 12, no. 2, pp. 71-76, 1998.

[8] H. A. Al-Sanad, W. K. Eid, and N. F. Ismael, "Geotechnical properties of oil-contaminated Kuwaiti sand," Journal of Geotechnical Engineering, vol. 121, no. 5, pp. 407-412, 1995.

[9] B. M. Sunil, S. Shrihari, and S. Nayak, "Shear strength characteristics and chemical characteristics of leachate-contaminated lateritic soil," Engineering Geology, vol. 106, no. 1-2, pp. 20-25, 2009.

[10] P. Ratnaweera and J. N. Meegoda, "Shear strength and stressstrain behavior of contaminated soil," Geotechnical Testing Journal, vol. 29, no. 2, pp. 133-140, 2006.

[11] M. G. A. Eltarabily, A. M. Negm, O. C. Saavedra Valeriano, and K. E. Gafar, "Effects of di-ammonium phosphate on hydraulic, compaction, and shear strength characteristic of sand and clay soils," Arabian Journal of Geosciences, vol. 8, no. 12, pp. 10419-10432, 2015.

[12] I. Gratchev and I. Towhata, "Stress-strain characteristics of two natural soils subjected to long-term acidic contamination," Soils and Foundations, vol. 53, no. 3, pp. 469-476, 2013.

[13] C. P. Zhu, H. L. Liu, and S. Yang, "Laboratory tests on shear strength properties of soil polluted by acid and alkali," Chinese Journal of Geotechnical Engineering, vol. 33, no. 7, pp. 1146-1152, 2010. 
[14] Q. Ma, X. Hu, Y. C. Yang, K. Jin, and X. T. Zhang, "Direct shear strength properties of clay polluted by hydrochloric acid," Electronic Journal of Geotechnical Engineering, vol. 22, no. 16, pp. 4447-4458, 2017.

[15] R. Alavéz-Ramírez, P. Montes-García, J. Martínez-Reyes, D. C. Altamirano-Juárez, and Y. Gochi-Ponce, "The use of sugarcane bagasse ash and lime to improve the durability and mechanical properties of compacted soil blocks," Construction and Building Materials, vol. 34, pp. 296-305, 2012.

[16] V. Robin, O. Cuisinier, F. Masrouri, and A. A. Javadi, "Chemo-mechanical modelling of lime treated soils," Applied Clay Science, vol. 95, no. 3, pp. 211-219, 2014.

[17] X. Zhang, M. Mavroulidou, and M. J. Gunn, "Mechanical properties and behaviour of a partially saturated lime-treated, high plasticity clay," Engineering Geology, vol. 193, pp. 320336, 2015.

[18] N. O. Attoh-Okine, "Lime treatment of laterite soils and gravels-revisited," Construction and Building Materials, vol. 9, no. 5, pp. 283-287, 1995.

[19] A. Sreekrishnavilasam, S. Rahardja, R. Kmetz, and M. Santagata, "Soil treatment using fresh and landfilled cement kiln dust," Construction and Building Materials, vol. 21, no. 2, pp. 318-327, 2007.

[20] T. Kamei, A. Ahmed, and T. Shibi, "Effect of freeze-thaw cycles on durability and strength of very soft clay soil stabilised with recycled Bassanite," Cold Regions Science and Technology, vol. 82, pp. 124-129, 2012.

[21] P. V. Sivapullaiah, J. P. Prashanth, A. Sridharan, and B. V. Narayana, "Technical Note Reactive silica and strength of fly ashes," Geotechnical and Geological Engineering, vol. 16, no. 3, pp. 239-250, 1998.

[22] S. R. Kaniraj and V. G. Havanagi, "Compressive strength of cement stabilized fly ash-soil mixtures," Cement and Concrete Research, vol. 29, no. 5, pp. 673-677, 1999.

[23] L. Makki-Szymkiewicz, A. Hibouche, S. Taibi, G. Herrier, D. Lesueur, and J.-M. Fleureau, "Evolution of the properties of lime-treated silty soil in a small experimental embankment," Engineering Geology, vol. 191, no. 29, pp. 8-22, 2015.

[24] M. A. Ismail, H. A. Joer, W. H. Sim, and M. F. Randolph, "Effect of cement type on shear behavior of cemented calcareous soil," Journal of Geotechnical and Geoenvironmental Engineering, vol. 128, no. 6, pp. 520-529, 2002.

[25] J. Prabakar and R. S. Sridhar, "Effect of random inclusion of sisal fibre on strength behaviour of soil," Construction and Building Materials, vol. 16, no. 2, pp. 123-131, 2002.

[26] Q. Ma, Y. C. Yang, H. L. Xiao, and W. Xing, "Studying shear performance of flax fiber-reinforced clay by triaxial test," Advances in Civil Engineering, vol. 2018, Article ID 1290572, 2018.

[27] S. Akbulut, S. Arasan, and E. Kalkan, "Modification of clayey soils using scrap tire rubber and synthetic fibers," Applied Clay Science, vol. 38, no. 1-2, pp. 23-32, 2007.

[28] Q. Ma, Q. Deng, J. Mou, S. Yang, and X. Zhang, "Large-scale direct shear test on scrap tire strip reinforced brick powder," Advances in Civil Engineering, vol. 2019, Article ID 6046037, 2019.

[29] C. S. Vieira and P. M. Pereira, "Use of recycled construction and demolition materials in geotechnical applications: a review," Resources, Conservation and Recycling, vol. 103, pp. 192-204, 2015.

[30] M. Touahamia, V. Sivakumar, and D. Mckelvey, "Shear strength of reinforced-recycled material," Construction and Building Materials, vol. 16, no. 6, pp. 331-339, 2002.
[31] L. L. Ekanayake and G. Ofori, "Building waste assessment score: design-based tool," Building and Environment, vol. 39, no. 7, pp. 851-861, 2004.

[32] W.-L. Huang, D.-H. Lin, N.-B. Chang, and K.-S. Lin, "Recycling of construction and demolition waste via a mechanical sorting process," Resources, Conservation and Recycling, vol. 37, no. 1, pp. 23-37, 2002.

[33] A. Nadler, E. Perfect, and B. D. Kay, "Effect of polyacrylamide application on the stability of dry and wet aggregates," Soil Science Society of America Journal, vol. 60, no. 2, pp. 555-561, 1996.

[34] G. J. Levy and W. P. Miller, "Polyacrylamide adsorption and aggregate stability," Soil and Tillage Research, vol. 51, no. 1-2, pp. 121-128, 1999.

[35] E. Botero, A. Ossa, G. Sherwell, and E. Ovando-Shelley, "Stress-strain behavior of a silty soil reinforced with polyethylene terephthalate (PET)," Geotextiles and Geomembranes, vol. 43, no. 4, pp. 363-369, 2015.

[36] People's Communications Press, The Professional Standards Compilation Group of People's Republic of China, JTG E402007, Highway Geotechnical Test Rules, People's Communications Press, Beijing, China, 2007.

[37] Z. Y. Chen, Soil Slope Stability Analysis Theory Methods and programs, China Water and Power Press, Beijing, China, 2003, in Chinese.

[38] T. H. Lu and Z. D. Liu, Advanced Soil Mechanics, Machinery Industry Press, Beijing, China, 2005, in Chinese. 


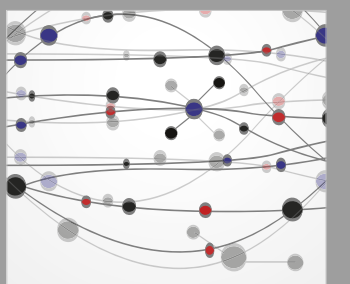

The Scientific World Journal
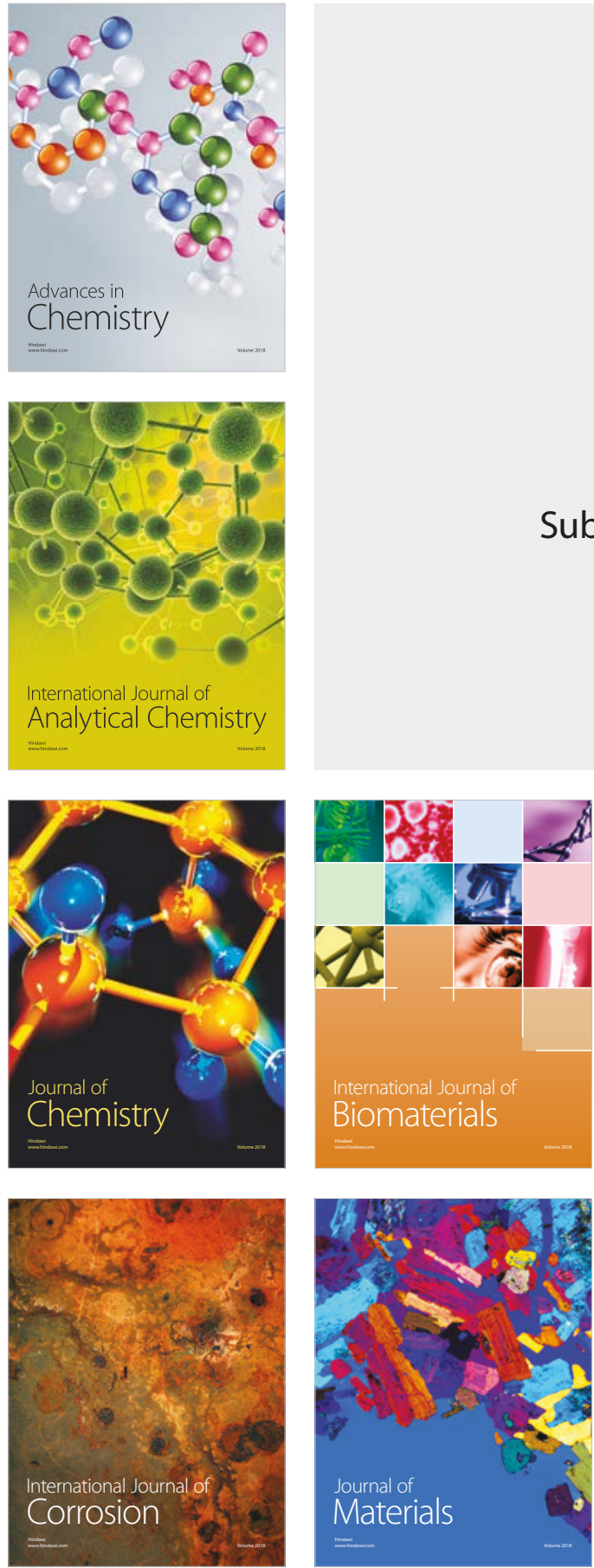

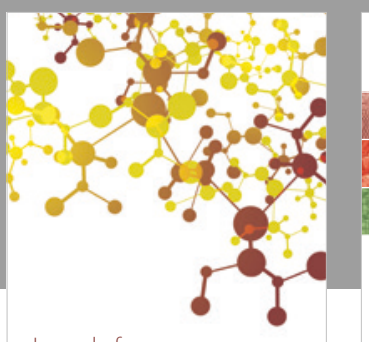

Journal of

Applied Chemistry
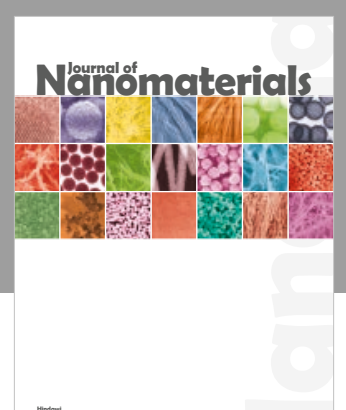

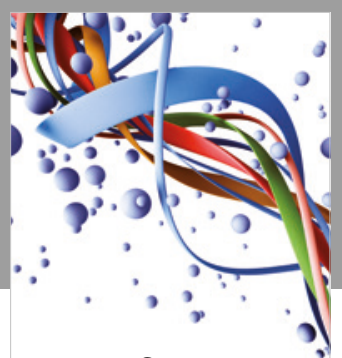

Scientifica

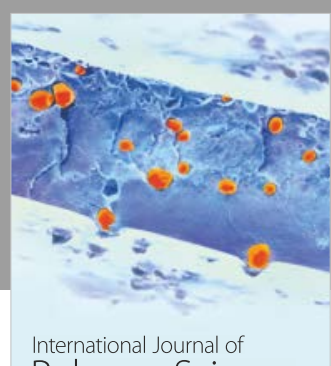

Polymer Science

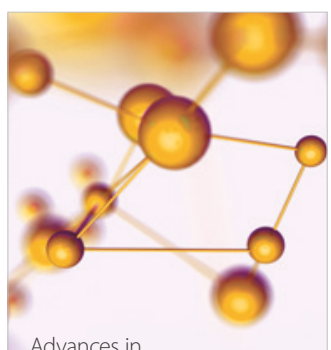

Physical Chemistry
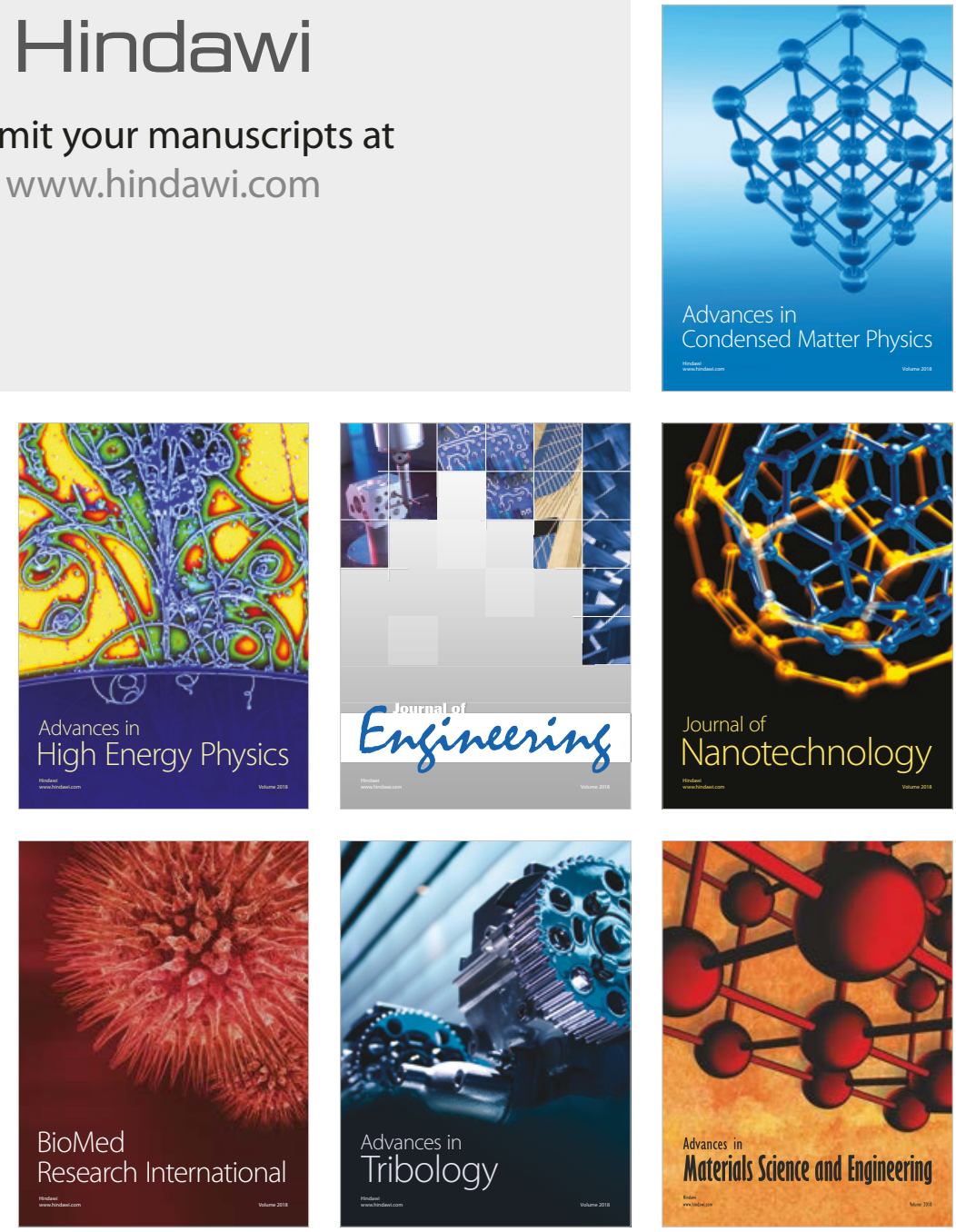